\title{
LED BASED UNIVERSAL LIGHTING SYSTEM
}

\author{
POSPISILIK, M[artin] \& ADAMEK, M[ilan]
}

\begin{abstract}
Recently, the LED based interior lighting systems are passing through the boom. LED lamps represent proven and energetically convenient technology. However, the technicians deal with several problems resulting from replacing the conventional light sources with LED lamps. One of the most disadvantageous differences between the conventional and LED lamps are the VA-characteristics of the LEDs' PN junctions. Unlike bulbs and fluorescent tubes, the LEDs must be supplied with constant DC current in order their stability in light flux and their nominal service time were reached. On the other hand, dealing with this disadvantage can lead to more universal and comfort solutions, as demonstrated in this paper. Because there are no general standards used at employing the LED lamps, in this paper we would like to introduce one of the possible solutions that contributes to higher variability and comfort of the interior lighting with LED lamps
\end{abstract}

Keywords:LED lamp, Intelligent building, Lighting system, Remote controlling

\section{INTRODUCTION}

Requiring the achievement of long service life of the LED lamps, there is always a need for a stabilised DC current source to supply the LEDs. If more LEDs are working simultaneously one of the most convenient solutions is to connect all LEDs in a serial way and feed them with the same current because due to technological deviations each of the LEDs can embody slightly different threshold voltage. The voltage needed to reach the required current then depends on how many LEDs are connected in series, in what region does their threshold voltage fluctuate and how big is the voltage drop at the rectifier and current source. Practically, it is hard to ensure that any configuration of the LED lamp can be supplied with the common AC $230 \mathrm{~V}$ power supply. Usually there is a need of some additional circuitry which is not always a disadvantage but which can rather be employed with many advantages. The additional circuitry allows creating more complex and modular systems being dimmed manually or by means of the remote controller. The design of one of such complex systems is described in this paper.

\section{MODULAR LIGHTING SYSTEM DESIGN}

The modular concept allows us to divide the lighting system into several parts. There can be two or three main units respectively - the DC power source, the control signal source and the controlled DC current source embedded in the proper LED lamp. In the solution described in this paper the two-unit system is described. It's block diagram can be seen in Fig. 1. The concept is based on a 100 LED stripe lamp with a dimmer. The lamp is supplied with $24 \mathrm{~V} \mathrm{DC}$ voltage and the proper DC/DC converter acting as a current source is embedded at the lamp while the controlling unit is joint with the 24 V DC switched-mode power supply.

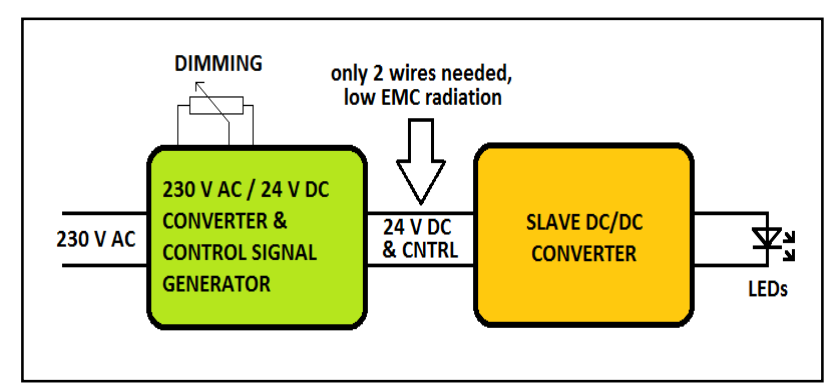

Fig. 1. Modular lighting system block diagram

As depicted in Fig. 1, the power supply and the controlling signal are delivered to the slave DC/DC converter embedded in the LED lamp via one pair of wires. The power supply can be, for example, embedded in the wall switch while the LED strip is mounted on the ceiling. In order the electromagnetic radiation from the wires was eliminated, it is convenient to feed the LED lamp with $24 \mathrm{~V}$ well filtered DC voltage while the controlling signal is a low-frequency sinusoid superimposed on the DC voltage. In this concept a sinusoidal voltage of $1 \mathrm{~V}$ was used. Its frequency is tuned according to the required dimming from 1 to $5 \mathrm{kHz}$. This solution provides one more advantage: By employing the $24 \mathrm{~V}$ supply voltage, also the accumulator sources charged by solar panels can be used and moreover, this lighting can be installed at dangerous places as bathrooms etc.

In addition, more lamps tuned at various frequencies can be fed with one wiring, being controlled separately. This system enables the following configurations:

- One supply source for more lamps. The lamps can be controlled at the same frequencies provided there are appropriate filters on the supply wiring. The controllers can be either analogous or microcontroller-based, placed always near the controlled lamp.

- One supply source for more lamps. Each lamp is controlled in different frequency range. This configuration enables to control the lamps not only by local controllers, either analogous or microcontrollerbased, but also centrally, using a programmable central controller. 
- Each lamp employs its own supply source and the controller. The risk of interferences between the controllers is minimized.

- The controller is integrated in the lamp and remote controller is employed. The light can be switched on/off by switching the power supply.

\subsection{AC/DC Converter and control signal generator}

The AC/DC converter employs a switched-mode power supply driven by a TOP-switch-type integrated circuit TNY267. This power supply delivers $24 \mathrm{~V}$ to feed the lamp. Moreover, a simple adjustable sinus generator is embedded in the power supply block. The example of a connection diagram can be seen in Fig. 2 .

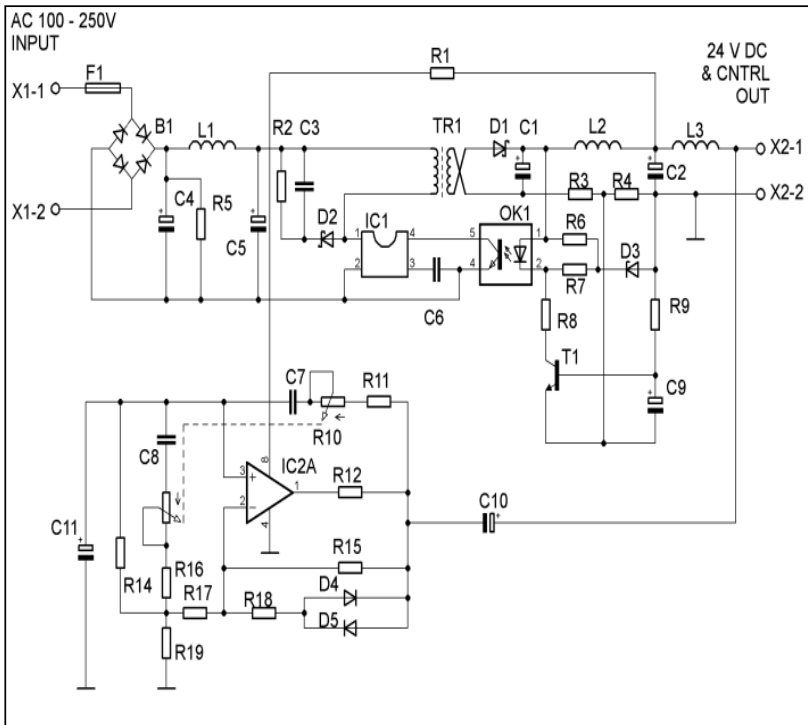

Fig. 2. AC/DC converter and control signal generator example

The schematic depicted in Fig. 2 is as simple as possible in order it could be embedded into a conventional wall switch. Most of the devices can be of SMD type. The power supply voltage is rectified by B1 rectifier and filtered by the filter made with $\mathrm{C} 1, \mathrm{~L} 1$ and C2. The impulse transformer is driven by IC1 (TNY267) chip, which is controlled by the OC1 optocoupler. The optocoupler is activated when there is overvoltage at the output behind the rectifying Schottky diode D2 (the threshold depends on the values of a Zener diode D3 and the resistor R7) or if the output current is exceeded (the voltage drop at the resistors $\mathrm{R} 3$ and $\mathrm{R} 4$ opens the transistor T1). The output filter C4, L2 and C5 ensures the output voltage to be smooth without ripple. The filter L3 and C5 decouples the sinusoidal controlling signal generated by the bridge oscillator with IC2 (any cheap operational amplifier, e.g. TL061). The oscillator runs at the frequencies from $1 \mathrm{kHz}$ to $5 \mathrm{kHz}$ according to the setting of the double potentiometer R10. Its negative feedback is nonlinear, employing diodes D4 and D5 in order to stabilise the output amplitude at approximately 1 $\mathrm{V}$ through the whole frequency range. The inductance of L3 should be at least $22 \mathrm{mH}$.

\subsection{Slave switching mode current regulator}

The example of a slave switching mode current regulator is depicted in Fig. 3.

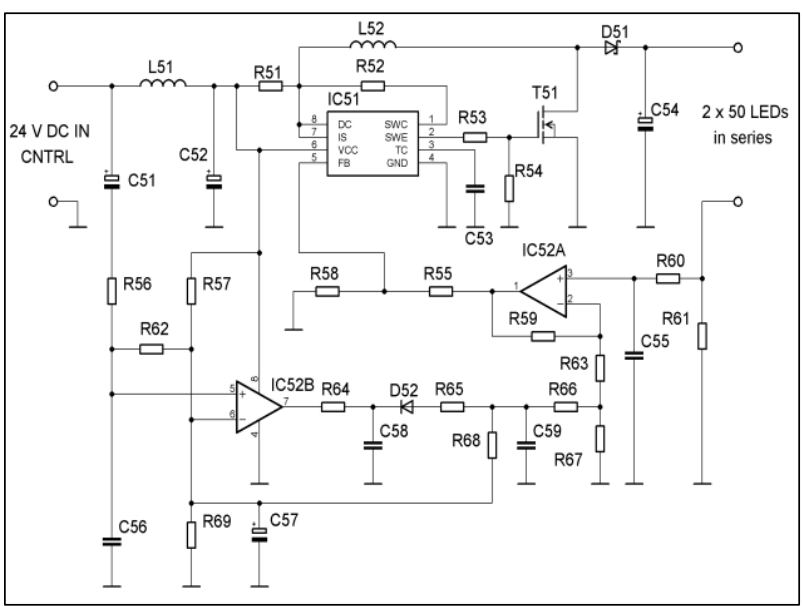

Fig. 3. Example of slave current regulator

The regulator is implemented in the LED lamp, being fed by the $24 \mathrm{~V} \mathrm{DC}$ power supply and the control signal superimposed on the power supply voltage. The control signal is decoupled by the filter made of the inductor L51 and the capacitor C52. The IC51 (MC34063 voltage converter), together with T51 and L52, act as a step-up voltage converter. There is a comparator embedded in the MC34063 chip that disables its operation when there is a feedback voltage higher than $1.25 \mathrm{~V}$. The feedback in this circuit is ensured by the IC52a operational amplifier that, together with R61, converts the current through the LEDs in the lamp to the output voltage. The feedback voltage is then delivered to the IC51 via the voltage divider with R55 and R58. Moreover, the bias of the current-to-voltage converter can be adjusted by the external current flowing through R66. Using the superposition principle, the following equation for the IC52a output voltage can be deduced:

$$
U_{\text {OUT }}=\left(1+\frac{R 59}{R 63+R 67}\right) \cdot U^{+}-\frac{R 59}{R 63+R 66} \cdot U^{-}[V]
$$

Where:

- $\mathrm{U}_{\text {OUT }}$ is the output voltage of IC52a,

- $\mathrm{U}^{+}$is the voltage at the non-inverting input of IC52a,

- $\mathrm{U}^{-}$is the voltage at C59 and other members are the resistances of the appropriate resistors (see Fig. 3).

The "bias" voltage at C59 is generated as follows: The sinusoidal control voltage passes through C51 and drives the operational amplifier IC52b that works as a comparator. It serves to shape the signal to a rectangular type with the known amplitude (the amplitude is defined by the stabilised input voltage). At the output of IC52b there are rectangular pulses with $50 \%$ duty cycle the period of which corresponds to the frequency of the sinusoidal signal with no respect to its amplitude. By R64 and C58 this signal is integrated. The higher the frequency is, the lower is the amplitude at C58 while the DC component stays unchanged (because the duty cycle is still $50 \%$ ). The C59 is charged to the half of the DC supply voltage throught the resistor R58, but it is also discharged via D52 if the voltage at C58 drops down. After a short period of time the voltage at C59 
corresponds to the bottom value of the voltage swing at C58. The lower the controlling frequency is, the higher is the swing and the lower is the voltage at C59 which, according to 1 , results in higher feedback voltage, leading to lower LEDs current. If no control signal exists, the LEDs current is regulated at high levels, which enables the operation of the lamp simply without any dimmer, assuring higher flexibility of this design.

\section{PROGRESSIVE INTEGRATED CURRENT REGULATOR AND ITS UTILIZATION}

Currently, there are many of suitable current regulators to be implemented in the LED lamps. As the example of such switching-mode operated regulator, HV9910B can be considered. Its basic connection is depicted in Fig. 4.

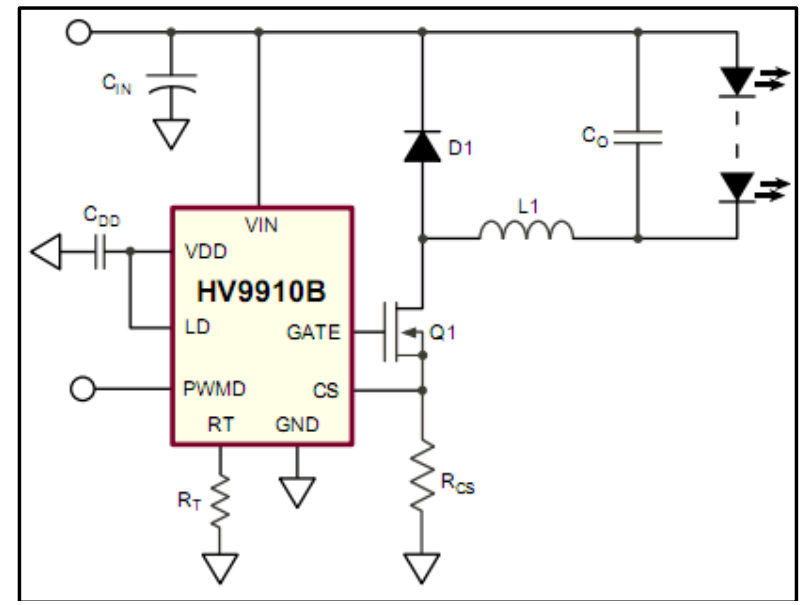

Fig. 4. Basic connection of HV9910B [6]

The Figure 5 shows a possible connection of the HV9910B controller in a low-voltage application with only one power LED employed. The integrated circuit LM555 marked as U1 generates a PWM signal proportional to the setting of a potentiometer P1. This signal is fed to the PWMD input of the HV9910B marked as U2. The LED-lamp is connectet to the J2 socket. Because only one white high-current LED is employed in this application, the voltage in the prototype circuit has been reduced to 5 volts.

According to the documentation, also a buck-boost connection of HV9910B is possible, as depicted in Fig. 6. With this connection, up to 8 pieces of $350 \mathrm{~mA}$ LEDs can be driven with the efficiency up to $90 \%$ [6], employing the supply voltage from 8 to $300 \mathrm{~V}_{\mathrm{DC}}$. This enables to construct the considered remotely-controlled lamp using the supply voltage of $24 \mathrm{~V}$ with the controlling signal fed through the supply line. The dimming of the LEDs then can be processed by means of the LD input of the circuit, according to the DC voltage obtained from the $\mathrm{f} / \mathrm{U}$ converter. The example of a simple $\mathrm{f} / \mathrm{U}$ converter connection is depicted in Fig. 7.

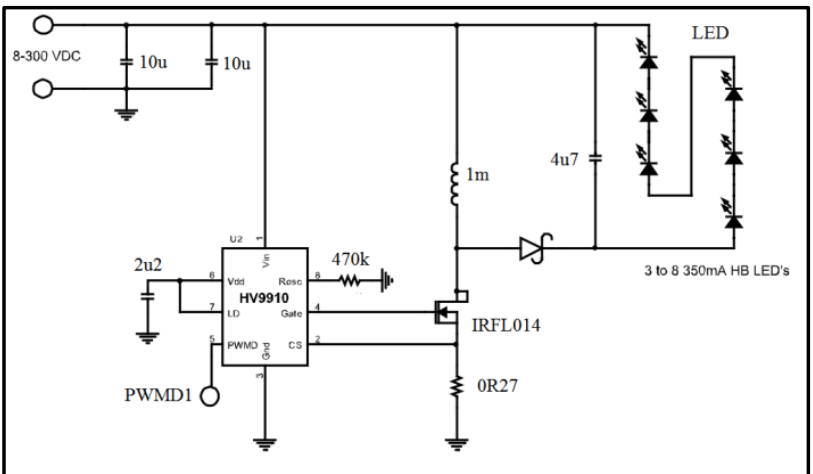

Fig. 6. Buck - boost connection of the LED current controller with HV9910 [6]

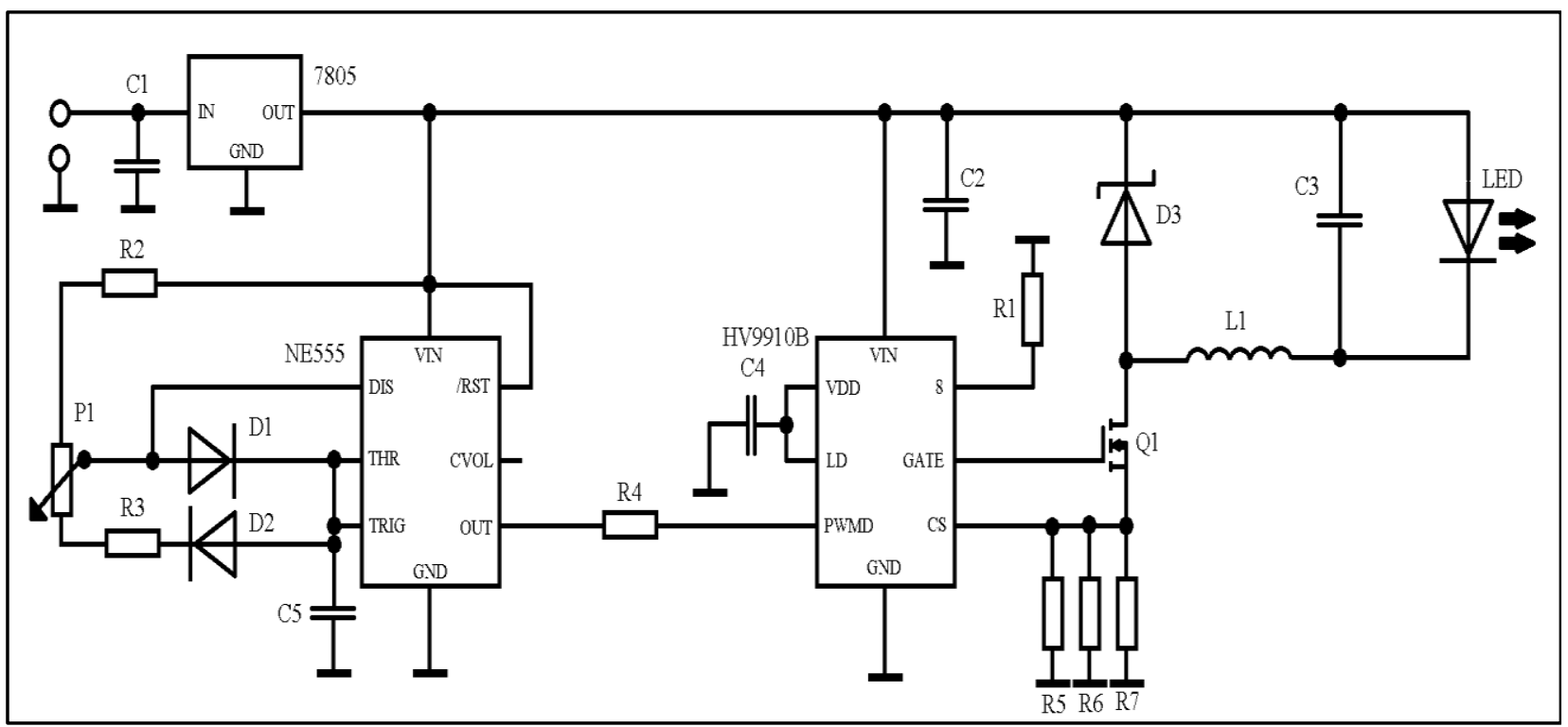

Fig. 5. Example of a dimmer employing HV9910B [5] 


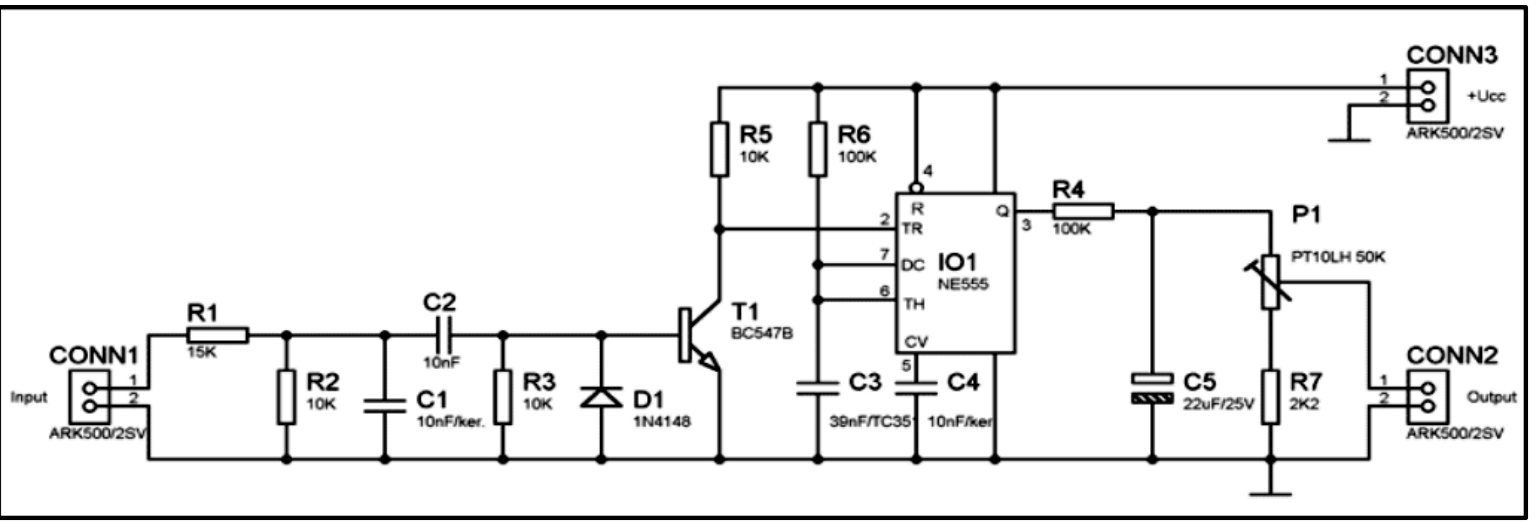

Fig. 7. Example of a simple f/U converter [7]

Provided the circuits from Fig. 6 and Fig. 7 are employed together with the AC/DC converter and control signal generator depicted in Fig. 2, the block diagram of the whole system can be depicted according to Fig. 8 .

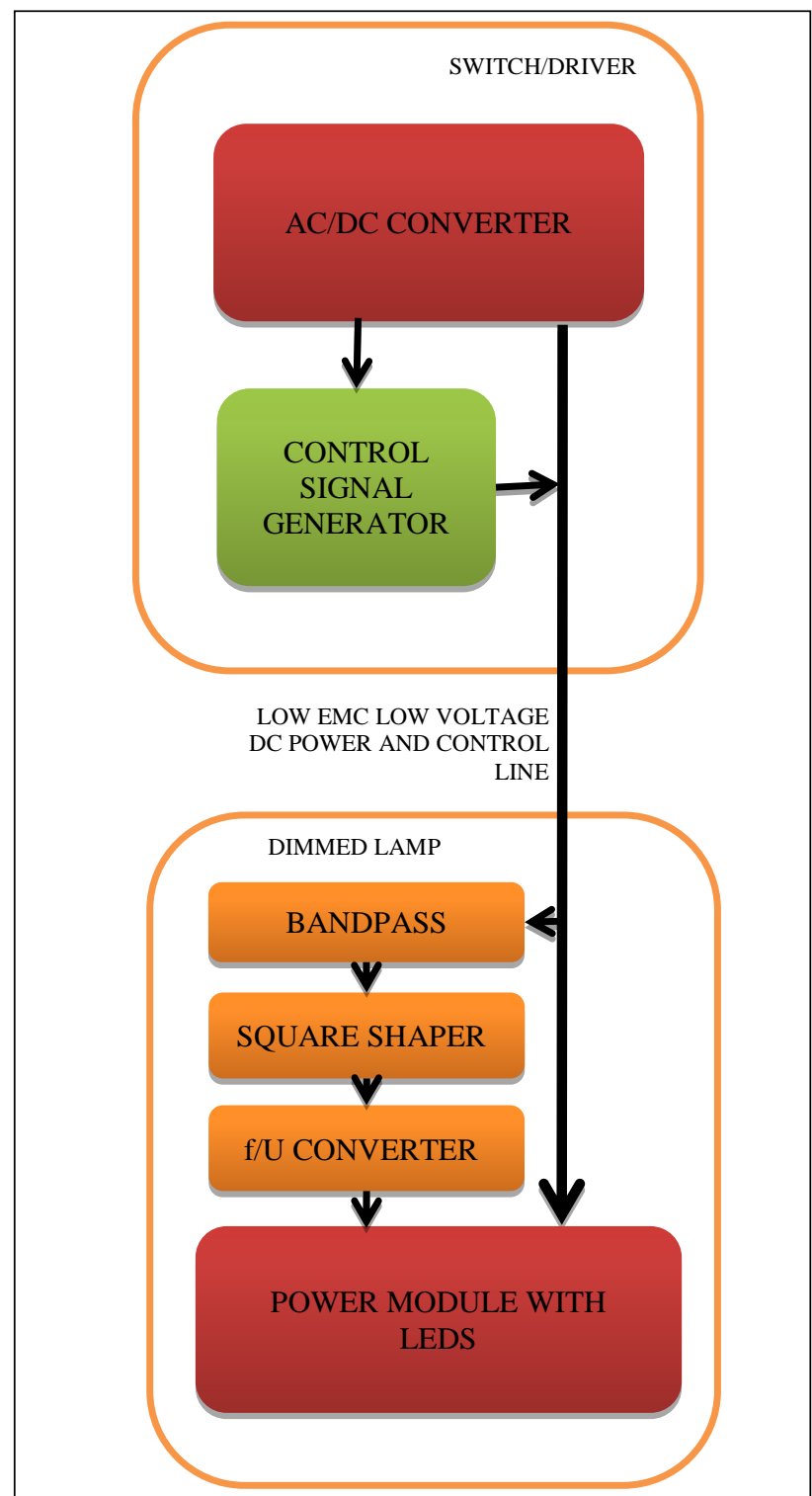

Fig. 8. Progressive remotely-controlled low voltage dimmed lamp system
The system depicted in Fig. 8 considers the control signal generator included in the switch or AC/DC converter but as stated in the text both modules can be separated, enabling to control the lamps in a decentralized way. Each lamp includes a bandpass filter selecting its proper control signal, signal shaper in order the proper function of the $f / U$ converter was ensured and the $f / U$ converter that drives the power module feeding the LEDs.

\section{CONCLUSION}

In this paper the possibilities of the decentralised LED home lighting system construction are discussed. The authors propose to employ a safe $24 \mathrm{~V}$ DC supply mains on which a frequency modulated controlling signal is superimposed. This construction enables to drive the different lamps from one point as well as to drive each lamp with its own switch/controller.

\section{ACKNOWLEDGMENT}

This paper is supported by the Internal Grant Agency at TBU in Zlin, project No. IGA/45/FAI/10/D and by the European Regional Development Fund under the project CEBIA-Tech No. CZ.1.05/2.1.00/03.0089.

\section{REFERENCES}

[1] Punčochář, J. (1999). Operational amplifiers in electrotechnics [Operační zesilovače v elektronice]. BEN, ISBN 80-86056-37-6, Praha

[2] Neumann, P., Uhlír J. (2001). Electronic circuits and functional blocks I [Elektronické obvody a funkčni bloky I]. Vydavatelství ČVUT, ISBN 80-01-02394-X, Praha

[3] http://www.onsemi.com/pub_link/Collateral/ MC34063AD.PDF(2010) - MC34063 application information: Accessed on: 2011-08-22

[4] http://www.digchip.com/datasheets/parts/datasheet 1373/TNY267.php (2010) - TNY267 application information. Accessed on: 2011-08-23

[5] Zatloukal, J., Advanced decentralised controller of home LED light, diploma thesis, Tomas Bata University in Zlin, Czech Republic, 2012

[6] http://www.premier-electric.com/files/supertex/pdf/hv9910.pdf (2012) - HV9910B datasheet, : 2012-08-22

[7] http://www.hw.cz/teorie-a-praxe/konstrukce/autotester-digitalniotackomer-0-7000-otmin.html,(2006) , "Digital RPM meter", Accessed on: 2012-05-20 